\title{
DRESS SYNDROME- A RARE CONDITION
}

\author{
HOMAYRA TAHSEEN HOSSAIN ${ }^{1}$, QUAZI TARIKUL ISLAM ${ }^{2}$, ISHRAT BINTE REZA ${ }^{3}$, TASMINA \\ CHOWDHURY $^{4}$, MD. MAKSUDUL MAZUMDER ${ }^{5}$, HAM NAZMUL AHASAN ${ }^{6}$
}

\begin{abstract}
:
DRESS syndrome (Drug reaction with Eosinophilia and Systemic Symptoms) is a rare but potentially life-threatening drug hypersensitivity reaction characterized by fever, exfoliative dermatitis and maculopapular rash, lymphadenopathy, eosinophilia, leucocytosis, and involvement of internal organs as liver, lung, heart, and kidney. The disorder starts within 2-8 weeks after taking an offending drug. Long latency between drug treatment and onset of symptoms along with variability of presentation make the diagnosis quite difficult. Here, we are presenting a case report of 58 year old male presented with short history of high grade fever with extensive skin rash. Investigations revealed leucocytosis with gross eosinophilia. He gave history of taking carbamazepine for more than last 3 months prescribed by his neurologist. According to the RegiSCAR scoring system, our case could be classified as definite DRESS syndrome. After withdrawal of the offending drug carbamazepine and starting high dose of systemic corticosteroid, he improved dramatically. As this syndrome is quite uncommon, so we are reporting this case.
\end{abstract}

Key words: DRESS syndrome, Eosinophilia, hypersensitivity reaction, RegiSCAR scoring system Introduction:

Received: 30 May 2018

Accepted: 10 June 2018

DOI: http://dx.doi.org/ 10.3329/bjmed.v29i2.37945

The term "Drug Rash with Eosinophilia and Systemic Symptoms" (DRESS) syndrome was first described in 1996 by Bocquet et al. (1) as a severe adverse drug reaction. DRESS syndrome is classified as one form of severe cutaneous adverse reactions (SCARs). In addition to DRESS syndrome, SCARs includes four other drug-induced skin reactions, the StevensJohnson syndrome (SJS); Toxic epidermal necrolysis (TEN), Stevens-Johnson/toxic epidermal necrolysis overlap syndrome (SJS/TEN); and Acute generalized exanthematous pustulosis (AGEP) ${ }^{2}$.

DRESS syndrome most commonly manifests two to eight weeks after starting the offending medicine, with a mean onset of three weeks ${ }^{3}$. DRESS syndrome is a delayed type IVb hypersensitivity reaction. The clinical triad consists of fever, skin rash and internal organ involvement. Laboratory tests usually show haematological disturbances including eosinophilia and atypical lymphocytes.
The estimated incidence of this potentially life threatening syndrome was reported in a range from 1 in 1,000 to 1 in 10,000 drug exposures, with a mortality rate up to $10 \%$, mostly caused by fulminant liver failure ${ }^{4}$. The drugs most often implicated are anticonvulsants, bupropion, sulfonamides, sulfasalazine, allopurinol, minocycline, abacavir and neviparine. Prompt clinical recognition and discontinuing suspected medicines helps to minimise morbidity and mortality associated with this syndrome. Systemic steroids are commonly used as well but no controlled clinical trials assess the efficacy of this treatment ${ }^{5}$.

Here, we are presenting a case report of a 58 year old male presented with short history of high grade fever with extensive skin rash \& gross eosinophilia. He had a history of taking Carbamazepine for seizure disorder for more than last 3 months. We labelled him as DRESS syndrome \& treated accordingly.

1. Associate Professor, Medicine, Popular Medical College Hospital, Dhaka

2. Professor\& Head of Medicine, Popular Medical College Hospital, Dhaka

3. Registrar, Medicine, Popular Medical College Hospital, Dhaka

4. Registrar, Medicine, Popular Medical College Hospital, Dhaka

5. Registrar, Medicine, Popular Medical College Hospital, Dhaka

6. Professor\& Head of Medicine, Popular Medical College Hospital, Dhaka

Address of correspondence: Dr. Homayra Tahseen Hossain (FCPS, MRCP), Associate Professor, Medicine, Popular Medical College Hospital, Dhaka. Email: homayra.tahseen@gmail.com

Bangladesh J Medicine 2018; 29 : 91-93 


\section{Case report:}

Our patient was a 58-year-old diabetic, hypertensive, Muslim male, presented to Medicine OPD with the complaints of fever for 6 days, generalized itchy reddish rash for 3 days, anorexia, nausea, generalized weakness, severe sole pain with walking difficulties for 2 days. His fever was high grade, highest recorded temperature was $104^{æ \%} \mathrm{~F}$. It was initially associated with chills \& rigor. There was no respiratory, abdominal or urinary complain associated with fever. His diabetes \& hypertension was well controlled with medications. He was taking Carbamazepine for some abnormal motor movements prescribed by his neurologist for more than last 3 months.

Examination revealed, the patient was febrile, toxic, flushed in appearance. He was alert \& well oriented. There was diffuse erythematous maculopapular rash involving trunk \& extremities. He had facial \& periorbital oedema. Initially, his palms \& soles were spared, but later on, after 2 days of hospitalization, there was erythematous scaly rash involving his palms $\&$ soles also. There was pedal oedema. On admission, his systemic examination was unremarkable.

After getting leucocytosis, we started broad spectrum antibiotics along with antihistamin for itching. But 2 days after hospitalization, there was no improvement, rather his condition deteriorated. He was still febrile, toxic, flushed, having facial oedema. Rash increased, involving his palms \& soles. There was cheilitis, he was unable to eat adequately. He developed dry cough. Examination

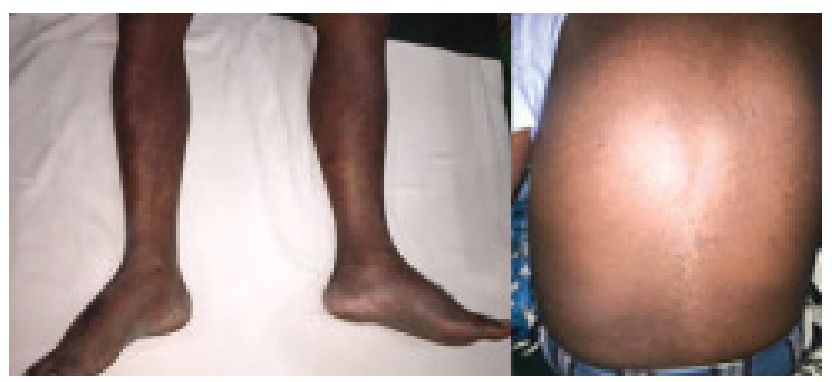

Fig.-1: Erythematous rash involving lower limbs \& trunk. revealed coarse crackles at lung base (left side); which was initially clear. We reviewed CBC, which revealed 35\% Eosinophil count. FDP \& D-dimer were raised.

Fever with extensive rash with gross eosinophilia along with history of carbamazepine intake pointed towards the diagnosis of DRESS syndrome. Carbamazepine was stopped on admission. After labelling the patient as DRESS syndrome, we started high dose systemic steroid (Intravenous Methyl prednisolone for 3 days, followed by oral Deflazacort).

Just after a day of starting systemic steroid, his condition improved dramatically. Gradually he became afebrile, rashes started to resolve, his general wellbeing improved. Laboratory parameters also improved, Eosinophil count came down to $1 \%$.

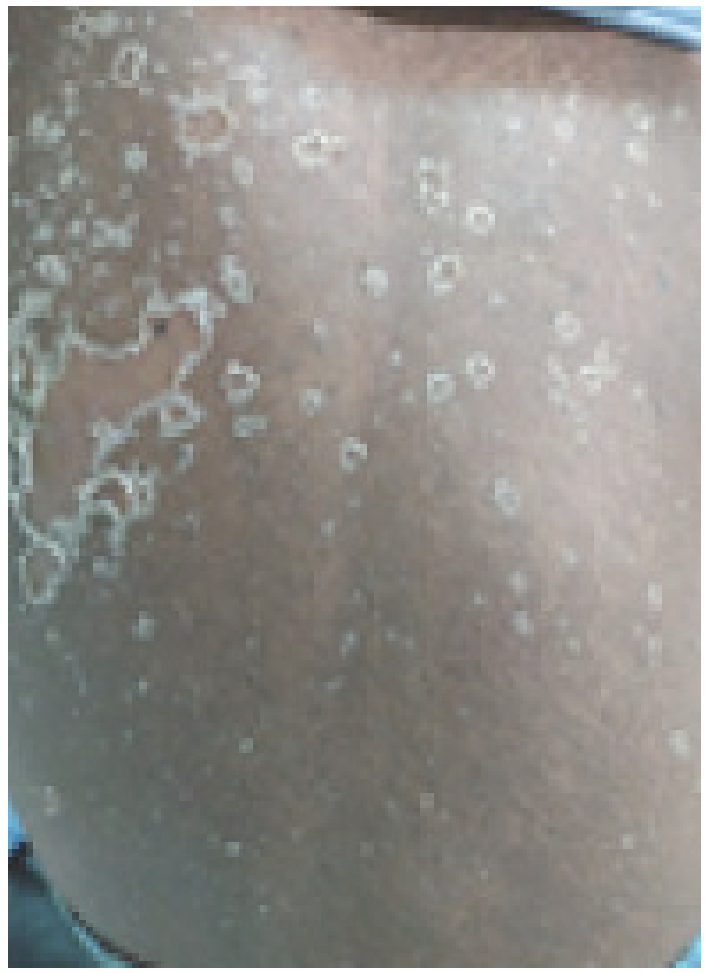

Fig.-2: Rashes of trunk in resolution

Investigations done on admission revealed-

\begin{tabular}{lll}
\hline Investigation & Findings & Remarks \\
\hline CBC with comment on Peripheral & Total count-17120/ mm3, N-60\%, & Leucocytosis with \\
Blood Film & E-23\%, PC-2,45,000/mm³, PBF- gross & eosinophilia \\
& eosinophilia & \\
ALT & $113 \mathrm{U} / \mathrm{L}($ normal upto 41 U/L) & Increased ALT \\
S. creatinine & $1.09 \mathrm{mg} / \mathrm{dl}$ & Normal \\
S. Electrolytes & Na-125, K-3.22, Cl-92, HCO3-28 & Hyponatraemia, Hypokalaemia \\
Dengue \& Chikungunya serology & Negative & \\
Urine R/E & Normal & \\
Blood C/S & No growth & \\
\hline
\end{tabular}




\section{Discussion:}

DRESS syndrome is an often under-diagnosed and under-recognized severe type IV (delayed type) hypersensitivity reaction that can occur with any medication but most commonly in response to aromatic anticonvulsants ${ }^{6}$. The diagnosis of DRESS syndrome is mainly clinical. The latency period, diversity of symptoms, and exclusion of similar nondrug-induced conditions should be under consideration. Multiple diagnostic criteria have been developed and used in order to standardize the diagnosis and management of DRESS, albeit with limited success. The RegiSCAR group suggested criteria for hospitalized patients with a drug rash to diagnose DRESS syndrome.

RegiSCAR criteria for diagnosis of DRESS ${ }^{7}$

1. Hospitalization

2. Reaction suspected to be drug-related

3. Acute rash

4. Fever $>38^{\circ} \mathrm{C}^{*}$

5. Enlarged lymph nodes at a minimum of 2 sites*

6. Involvement of at least 1 internal organ*

7. Blood count abnormalities* (lymphopenia or lymphocytosis, eosinophilia, thrombocytopenia)

8. Severe Nerve Pain

*Three out of four asterisked (*) criteria are required for making the diagnosis.

Our patient fulfilled the diagnostic criteria, having high grade fever, involvement of internal organ liver as manifested by raised ALT \& lungs as manifested by features of pneumonia along with blood count abnormalities in the form of leucocytosis with eosinophilia.

Early recognition of the adverse drug reaction and discontinuation of offending medication are essential steps in limiting the progression of DRESS syndrome, as we have done in our case. Pharmacological treatment of DRESS syndrome has to date not been studied with randomized controlled trials and instead has been established on the basis of case reports and retrospective analysis. The French Society of Dermatology published a report in 2010 outlining a consensus on therapeutic management of DRESS syndrome ${ }^{8}$. They recommend the use of systemic corticosteroids at a dose equivalent to one $\mathrm{mg} / \mathrm{kg} /$ day of prednisone in patients with any sign of severity. If symptoms continue to progress despite the use of corticosteroids, other options include intravenous immunoglobulin (IVIG) and/or plasmapheresis ${ }^{9}$. Our patient responded well both clinically \& biochemically after starting treatment with high dose systemic steroid in the form of Methyl prednisolone.
As the diagnosis of DRESS syndrome is mainly clinical, the clinicians have to play the crucial role for prompt clinical recognition and discontinuing suspected medicines which will help to minimise the morbidity and mortality associated with this syndrome.

\section{Consent:}

Informed consent was obtained from the patient for publication of this case report and any accompanying images.

\section{References:}

1. Bocquet H, Bagot M, Roujeau JC. Drug-induced pseudolymphoma and drug hypersensitivity syndrome (Drug Rash with Eosinophilia and Systemic Symptoms: DRESS) Semin Cutan Med Surg. 1996;15:250-7. (http://dx.doi.org/10.1016/S10855629(96) 80038-1.

2. Walsh SA, Creamer D (January 2011). "Drug reaction with eosinophilia and systemic symptoms (DRESS): a clinical update and review of current thinking". Clinical and Experimental Dermatology. 36 (1): 611. (doi:10.1111/j.1365-2230.2010.03967.x.

3. Seth D et al (2008) DRESS syndrome: A practical approach for primary care practitioners. Clinical Paediatrics. 47(9):947-52.

4. Cacoub P, Musette P, Descamps V, Meyer O, Speirs C, Finzi L, et al. The DRESS syndrome: a literature review. Am J Med. 2011;124:588-97. http:// dx.doi.org/10.1016/ j.amjmed.2011.01.017. [PubMed]

5. Ganeva M, et al. (2008). "Carbamazepine-induced drug reaction with eosinophilia and systemic symptoms (DRESS) syndrome: report of four cases and brief review". International Journal of Dermatology. 47 (8): 853-860. doi:10.1111/j.13654632.2008.03637

6. Carroll MC, Yueng-Yue KA, Esterly NB, Drolet BA: Drug-induced hypersensitivity syndrome in pediatric patients. Pediatrics. 2001, 108 (2): 485492. 10.1542/ peds. 108.2.485.

7. Eshki M, AUanore L, Musette P, et al. Twelve-year analysis of severe cases of drug reaction with eosinophilia and systemic symptoms: a cause of unpredictable multiorgan failure. Arch Dermatol. 2009;145:67-72.

8. Descamps V, Ben-Saïd B, Sassolas B, Truchetet F, Avenel-Audran M, Girardin P, Guinnepain MT, Mathelier-Fusade P, Assier H, Milpied B, Modiano $\mathrm{P}$, Lebrun-Vignes B, Barbaud A, groupe Toxidermies de la Société française de dermatologie: Management of drug reaction with eosinophilia and systemic symptoms (DRESS). Ann Dermatol Venereol. 2010, 137: 703-708. 10.1016/j.annder.2010.04.024.

9. Criado PR, Criado RF, Jde Avancini M, Santi CG: Drug reaction with Eosinophilia and Systemic Symptoms (DRESS) / Drug-induced Hypersensitivity Syndrome (DIHS): a review of current concepts. An Bras Dermatol. 2012, 87 (3): 435-449. 10.1590/ S0365-05962012000300013. 